\title{
Erratum: Finite particle size drives defect-mediated domain structures in strongly confined colloidal liquid crystals
}

\author{
loana C. Gârlea, Pieter Mulder, José Alvarado, Oliver Dammone, Dirk G.A.L. Aarts, M. Pavlik Lettinga, \\ Gijsje H. Koenderink \& Bela M. Mulder
}

Nature Communications 7:12112 doi: 10.1038/ncomms12112 (2016); Published 29 Jun 2016; Updated 3 Aug 2016

The present address for Ioana C. Gârlea is incorrect in this Article. The correct present address for this author is given below:

Faculty of Physics, University of Vienna, Boltzmanngasse 5, A-1090 Vienna, Austria.

The name of this author is also incorrect in the 'How to cite this article' section. This section should read:

Gârlea, I. C. et al. Finite particle size drives defect-mediated domain structures in strongly confined colloidal liquid crystals. Nat. Commun. 7:12112 doi: 10.1038/ncomms12112 (2016).

(c) This work is licensed under a Creative Commons Attribution 4.0 International License. The images or other third party material in this article are included in the article's Creative Commons license, unless indicated otherwise in the credit line; if the material is not included under the Creative Commons license, users will need to obtain permission from the license holder to reproduce the material. To view a copy of this license, visit http://creativecommons.org/licenses/by/4.0/ 